\title{
Microencapsulation of Paraffin Wax in Melamine-Formaldehyde for use in Thermal Management Study
}

\author{
S.S. Pawar, C. Suryanarayana and A.B. Samui* \\ Naval Materials Research Laboratory Shil-Badlapur Road, PO. Anand Nagar, Additional Ambernath (East) \\ Dist-Thane-421506, India
}

\begin{abstract}
Melamine formaldehyde microcapsules containing paraffin wax as phase change material (PCM) were synthesized. Free space was generated in-situ inside microcapsules. These were characterized by FTIR Spectrophotometer, Scanning electron microscope (SEM), Differential Scanning colorimeter (DSC), and optical microscope. It was confirmed that PCM was successfully encapsulated inside the shell material. Encapsulated PCM showed good phase change properties during heating and cooling. Enthalpy value of about $100 \mathrm{~J} / \mathrm{g}$ was observed. The shape of the microcapsule, showing rough morphology is expected to help during processing and crystallization. It has been experimentally confirmed that no leakage occurs during the melting of PCM. Effectiveness in temperature control in a hot environment was also found to be satisfactory.
\end{abstract}

Keywords: Phase change materials, microencapsulation, melamine formaldehyde, thermal, management.

\section{INTRODUCTION}

Dissipation of heat generated by equipment kept in confined compartments/areas is a prerequisite for the satisfactory operation of electronic systems. Conventional cooling systems like air conditioning and the use of heat sinks are not viable options for temperature reduction in such areas where space is a limitation. The use of phase change material (PCM) can be considered as a promising method for the management of heat in the confined area. PCMs are environmentally benign salts or organic compounds, which store and release latent heat through a phase transformation [1-4]. PCM performs like conventional material i.e. its temperature raises as it is exposed to heat. However, near the melting point, it absorbs a large amount of heat without an increase in temperature accompanied by a change of phase. When the temperature drops below the melting temperature it solidifies, releasing its stored heat to the environment. Thus, PCM absorbs and emits heat while maintaining nearly a constant temperature [5]. Such materials store and release 2 to 14 times more thermal energy than conventional heat storage materials $[6,7]$. Paraffin wax, carboxylic acid, sodium sulfate decahydrate, calcium chloride hexahydrate etc. fall in the category of PCM, possessing such properties. Further, latent heat being quite appreciable, a relatively small amount of material will be required for large heat

*Address correspondence to this author at the Naval Materials Research Laboratory Shil-Badlapur Road, PO. Anand Nagar, Additional Ambernath (East) Dist-Thane-421506, India; Tel: +91-251-2623059;

Fax: +91-251-2623004; E-mail: absamui@gmail.com release. Hence these materials can be employed for efficient thermal management of systems having heat sources.

During the change from solid to liquid, PCMs start flowing. One of the main challenges in using PCM is the arrangement by which they are contained for repeated use. Various methods of containment have been reported in the literature $[7,8]$. PCMs are packed in aluminium, steel and plastic containers of various sizes and shapes and deployed appropriately in building for their functions [9]. It can also be impregnated into panel boards and concrete. Microencapsulated PCMs, when incorporated as filler in paint, can be used for thermal management [10]. Microcapsules, having large surface areas enable faster heat transfer between PCM and the environment [11]. Various methods are being followed for the preparation of microencapsulated materials such as vacuum encapsulation, spray drying, fluidized bed coating, electrostatic encapsulation [12] and complex coacervation of gelatin and gum arabic [13] interfacial polymerization [14]. The most common method is insitu polymerization [15].

Microencapsulated PCMs expand and contract during the phase change process of the core with an order of magnitude of $10 \%$ [16]. The difference in expansion coefficient between core and shell may lead to capsule rupture. Hence a free expansion space is required to be maintained inside the microcapsule which can prevent this rupture. Lee et al. [17] synthesized microcapsules by using a mixture of PCM and a volatile solvent as a core and subsequently, 
heat-treating the microcapsules in an oven at $100^{\circ} \mathrm{C}$ to remove the solvent and generate the space for expansion.

In this study, an attempt has been to encapsulate PCMs in-situ in an expanded state inside melamine formaldehyde (MF) microcapsules, well above its melting point. Microencapsulated PCMs were characterized by various analytical and instrumental methods. The performance of capsules as a heatregulating material was studied.

\section{EXPERIMENTAL}

\section{Materials}

Melamine $(99.9 \%)$ and paraffin wax were procured from Sigma Aldrich chemicals, formaldehyde (37 - 40\% W/V) from BDH chemicals, (India), sodium hydroxide and hydrochloric acid, from S.D. Fine chemicals (India) Limited. All chemicals were of analytical grade reagents and used as received without purification.

\section{Microcapsule Synthesis}

Microcapsules were synthesized by following the procedures of Lee et al. [17], and Zhang et al. [18]. Figure 1 shows the schematic of the synthesis procedure. Prepolymer solution was prepared by mixing $10.0 \mathrm{~g}$ of melamine, $19.5 \mathrm{~g}$ of formaldehyde in $20 \mathrm{ml}$ of distilled water. The solution was maintained at $\mathrm{pH} 9$ by using sodium hydroxide solution. The mixture was heated to $75^{\circ} \mathrm{C}$ under stirring. Stirring was continued till the mixture became transparent.

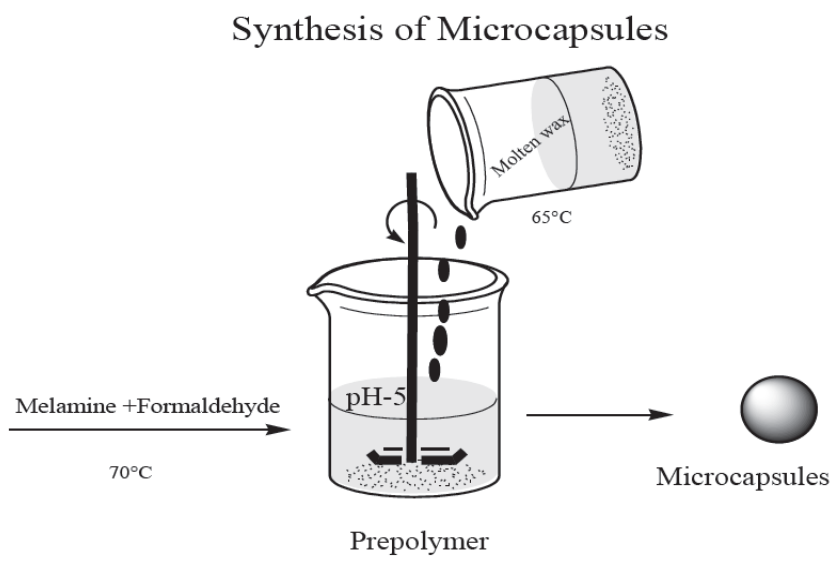

Figure 1: Schematic of Microcapsule synthesis.

$200 \mathrm{ml}$ of distilled water was taken in a separate beaker and heated up to $75^{\circ} \mathrm{C}$. Molten wax at $65^{\circ} \mathrm{C}$ was added under stirring to distilled water and agitated at $1000 \mathrm{rpm}$ for $15 \mathrm{~min}$. The $\mathrm{pH}$ of the mix was adjusted to 4 by using a hydrochloric acid solution. Prepolymer solution was added to the above mixture slowly under stirring and maintained at $75{ }^{\circ} \mathrm{C}$ for 1 hour. Microcapsules formed were separated by filtration, washed repeatedly with water, followed by nhexane and dried at ambient temperature under reduced pressure for 16 hours. Microcapsules were also prepared by varying the quantity of core material.

\section{Particle Size Analysis}

Particle size analysis was performed by using a particle size analyzer. (MASTERSIZER 2000, MALVERN, Worcestershire, UK). Microcapsules were dispersed in water. A drop of surfactant (Trton X-100) was added for the complete dispersion of microcapsules. The result was obtained as particle size distribution.

\section{Determination of Paraffin Wax in Microcapsules}

The amount of paraffin wax in a microcapsule was determined by extracting wax through soxhlation using n-hexane. A known weight of microcapsules was crushed and transferred to a weighed thimble. After 8 hours of extraction, the solvent with extracted wax was subjected to distillation. After most of the solvent was removed residue in the flask was transferred to a Petri dish and dried to constant weight in an oven at $85^{\circ} \mathrm{C}$.

\section{FTIR Spectroscopy}

Spectra of shell and core material extracted from soxhlet apparatus were recorded on an Infrared spectrophotometer (FTIR NICOLET 5700, Thermo electron scientific instruments, Madison, USA). Spectra was obtained in transmittance mode at a resolution of 4 $\mathrm{cm}^{-1}$ and 32 scans. Pellet was prepared by mixing shell and core materials separately with $\mathrm{KBr}$. FTIR spectra of pure wax and melamine formaldehyde resins were also recorded in a similar way.

\section{Thermal Analysis}

Wax, melamine formaldehyde and microcapsules with 80:20 core-shell ratio were characterized by DSC (Setsys TG-DSC 16, TA instruments. New castle, USA) in the temperature range of $25-250^{\circ} \mathrm{C} @ 20^{\circ} / \mathrm{min}$.

\section{Hot Stage Optical Microscope}

Microcapsule size, shape and melting of wax present in the capsule were examined by hot stage optical microscope (Leica DMLD). Microcapsules taken 
on a glass slide were kept on the platform of a hot stage microscope. The sample was slowly heated from ambient temperature to $65^{\circ} \mathrm{C}$, held for $2 \mathrm{~min}$ at $65^{\circ} \mathrm{C}$ and then cooled to ambient temperature. This process of heating and cooling was repeated 15 times. The entire process was recorded in a high-resolution camera.

\section{SEM Analysis}

Shell morphology and shell thickness measurements were carried by Scanning Electron Microscope (SEM) (Zeiss Leo, 1455 Scanning Electron Microscope / Oxford INCA EDS). Microcapsules were mixed with epoxy resin and polyamine hardener. The free film was prepared by pouring the mixture on selfrelease paper. After complete drying, microsphere incorporated film was fractured and the cross-section was examined under SEM. Prior to imaging test coupons were sputter-coated with gold.

\section{Performance Evaluation of Capsules}

PCM Microcapsules packed in a pouch was taken in a thermally insulated container fixed with the thermometer. A similar container containing a pouch with the same quantity of melamine formaldehyde resin powder (microcapsule shell material) was used as a control. An equal quantity of water, preheated to $85^{\circ} \mathrm{C}$, was poured into containers. The temperature of the containers was recorded continuously at regular time intervals.

\section{RESULTS AND DISCUSSION}

At melting temperature, the expansion coefficient of PCM is more than that of shell materials (such as melamine formaldehyde, urea formaldehyde etc.) in which they are encapsulated. Micro PCM expand and contract during the phase change process of the core to the extent of 10 volume $\%$. This difference in expansion leads to the rupture of the microcapsule. Maintaining free space inside the microcapsule will avoid aforesaid rupture at around melting temperature of the wax. It is reported [17] that free space inside the microcapsule can be generated by encapsulating PCM mixed with volatile solvent followed by heat-treating the microcapsules. During heat-treating, the solvent present in the capsule is removed and free space is generated. This is a two-step process.

We have adopted a novel technique of incorporation of wax in the microcapsule along with free space in absence of solvent. Volume expansion of PCM is directly proportional to the temperature. If the encapsulation process is carried out at a temperature higher than the melting point of PCM, it occupies more volume during the encapsulation process. When cooled to ambient temperature, volume contraction of the core will result in in-situ generation of free volume inside the capsule. It is known that the linear expansion coefficient of paraffin wax is $0.00011 \mathrm{k}^{-1}$. This is about $30 \%$ higher than that of polystyrene $[18,19]$. It is expected that for melamine formaldehyde this value will be similar or lower. The selection of this resin was, therefore, made to contain wax inside microcapsules. Further, the thermal conductivity of paraffin wax is found to be $0.25 \mathrm{wm}^{-1} \mathrm{k}^{-1}$ [20]. This value is lower than that of epoxy. The thermal conductivity of melamine formaldehyde resin is expected to be similar to that of epoxy. This indicates that heat flow through the shell will be reasonable. The characterization of the microcapsule and their performance evaluation are discussed in this paper.

Microcapsule core paraffin wax is soluble in nhexane whereas the shell is insoluble. When crushed capsules are extracted with n-hexane, wax dissolves in solvent leaving behind an insoluble melamine formaldehyde shell. From gravimetric estimation, it is found that core and shell materials are well present in capsule in $82: 18 \mathrm{wt}$. ratio.

\section{Particle Size Distribution Study}

PCM melts by absorbing heat from hot surroundings and solidifies liberating heat after reaching sub-melt temperature during the reverse process. Heat flow occurs through the surface of the PCM; the larger the surface area faster the heat flow. Usually during synthesis microcapsules of various sizes are formed. Figure 2 shows the particle size distribution of microcapsules as observed by the particle size analyzer. Size varies from $6 \mu \mathrm{m}$ to $1000 \mu \mathrm{m}$. However, most of the particles fall in the size ranges $90-400 \mu \mathrm{m}$. This is expected to be quite satisfactory for thermal management application.

\section{SEM Study}

Figure $3 \mathbf{a}$ and $\mathbf{b}$ shows the electron micrograph of fractured microcapsules. It is seen from SEM micrograph of wax microcapsule (a) that the microcapsule is spherical in shape and the shell is having rough morphology on its surface [21]. Such rough morphology of shell will provide good adhesion between microcapsule and resin matrix when 


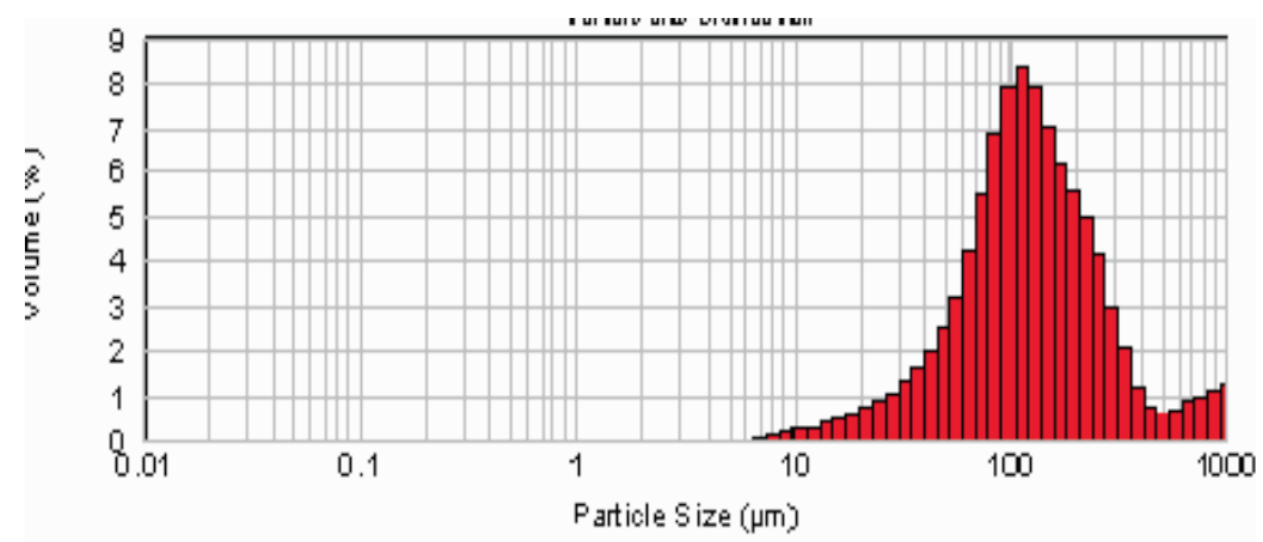

Figure 2: particle size analysis of microcapsules.

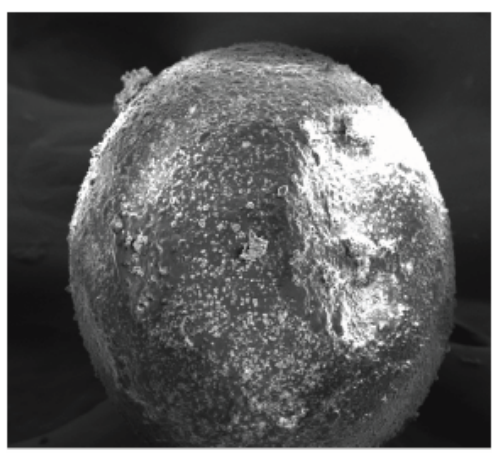

(a)

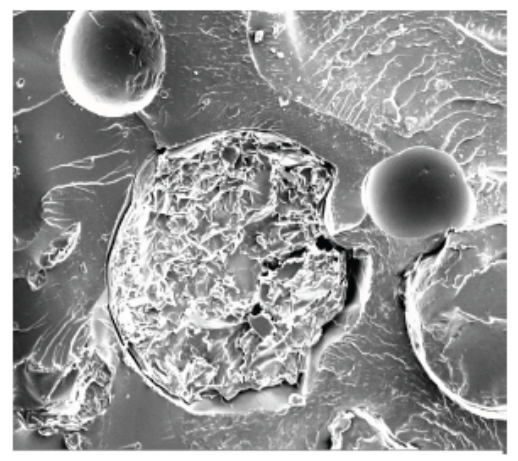

(b)

Figure 3: SEM Micrographs of (a) PCM capsules: (b) Half broken Capsule embedded in film.

incorporated in polymer matrix/coatings. The micrograph of a cross-section of film, containing halfbroken microcapsules, can be seen from $7(\mathrm{~b})$. The gap between the microcapsule shell and core can be clearly seen from this figure. This is what is exactly required for the melting/ solidification performance of encapsulated PCM. The thickness of the shell for $80: 20,75: 25$ and $65: 35$ compositions are in the range of $0.25-0.45 \mu \mathrm{m}$. As expected the thickness increases with an increase of shell material in the composition.

\section{FTIR Spectroscopy Analysis}

Figures 4 and 5 shows FTIR spectra of wax and extracted core. Both the spectra are closely matching with characteristic peaks for $\mathrm{C}-\mathrm{H}$ stretching and bending vibrations at $2915 \mathrm{~cm}^{-1}, 1474 \mathrm{~cm}^{-1}$ and $729 \mathrm{~cm}^{-1}$ respectively. This establishes that the wax is encapsulated in the side of the resin shell. Spectra of pure melamine formaldehyde resin and shell material are shown in Figure 3. Characteristic peaks of a $\mathrm{N}-\mathrm{H}$ stretching vibration at $1571 \mathrm{~cm}^{-1}$ and a small hump at around $3300 \mathrm{~cm}^{-1}$ are observed in both. $\mathrm{C}=\mathrm{O}$ stretching vibration at $1650 \mathrm{~cm}^{-1}, \mathrm{C}-\mathrm{H}$ stretching vibration at 1460 $\mathrm{cm}^{-1}, \mathrm{C}-\mathrm{N}$ stretching vibrations at 1286 and $1142 \mathrm{~cm}^{-1}$ are also present in both the spectra. This indicates that shell material consists of melamine formaldehyde resin [22].

\section{Thermal Analysis}

Figure 6 shows DSC thermogram for wax, It can be observed from curve (a) that two strong endothermic peaks appear at 40 and $55^{\circ} \mathrm{C}$ respectively. It is due to two stages of melting of wax, which may be due to different molecular weight fractions present in the wax. DSC thermogram of microcapsule (curve (b)) also shows endothermic peaks at 40 and $55^{\circ} \mathrm{C}$ corresponding to wax melting. The area under the melting peaks is used to calculate the latent heat of melting [23] of wax present in the capsule. The latent heat of melting of wax is found to be $18 \%$ more than that observed when present in the microcapsule. This is due to the fact that microcapsule contain both wax and melamine formaldehyde polymer (MF). Latent heat concerns the melting of the wax. There is no physical change of MF associated with latent heat. The total latent heat per unit weight of the capsule is, therefore, 


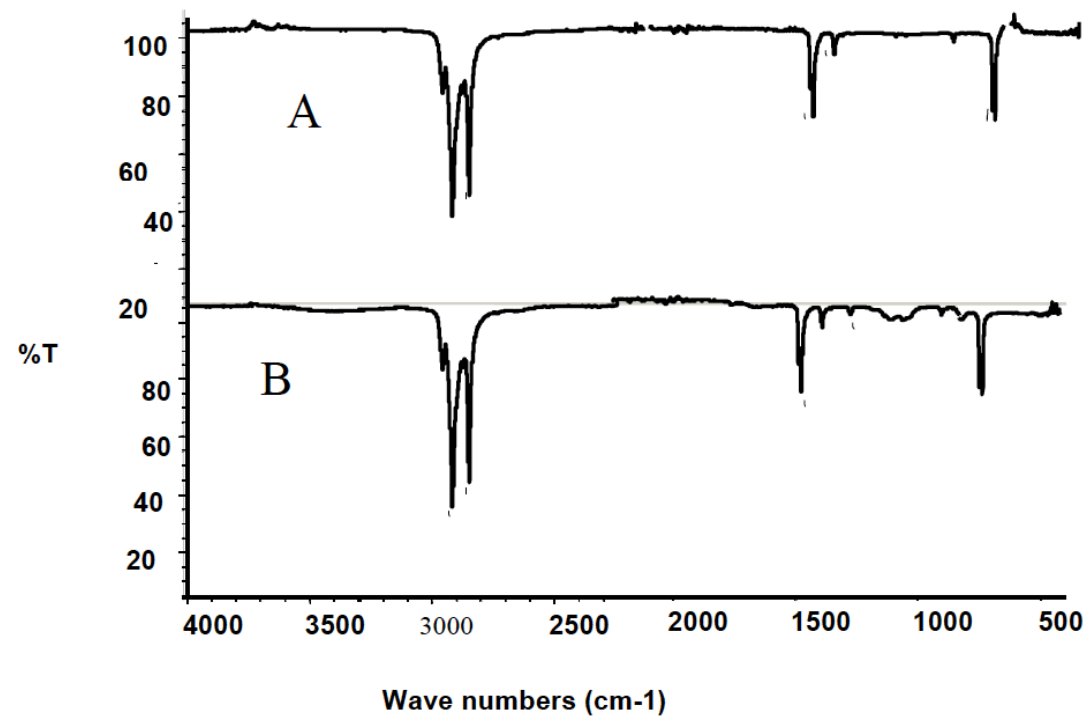

Figure 4: FTIR spectra of (A) wax, (B) core material of microcapsule.

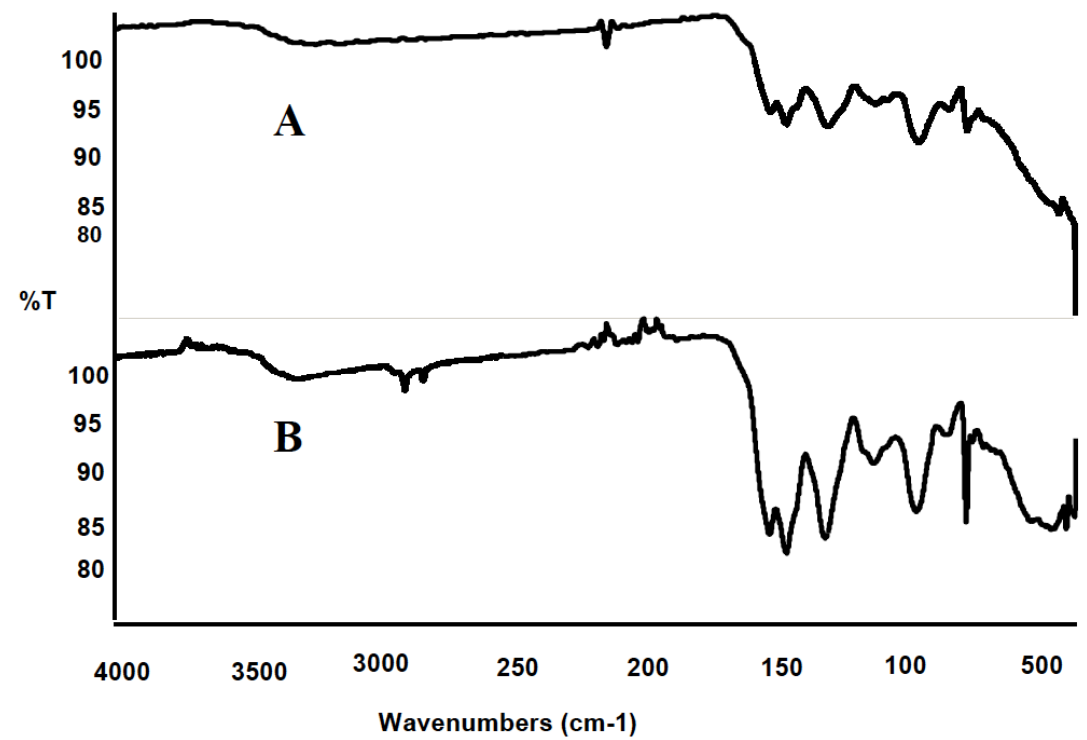

Figure 5: FTIR spectra of (A) Melamine formaldehyde, (B) shell material of microcapsule.

lower than pure wax. In addition to this presence of MF resin will also affect the crystallization which in-turn affects latent heat [24].

\section{Hot Stage Optical Microscope Study}

Microcapsules with varying core-shell ratios were evaluated for thermal stability on a hot stage optical microscope by heating above the melting temperature of the wax. With increasing core quantity the stability of microcapsules is found to decrease (Table 1). At 90:10 core-shell ratio, some free un-encapsulated wax was found to flow away at melting temperature wax. At 85:15 core-shell ratio, no free wax was found but capsules ruptured at a temperature slightly above the melting temperature of the wax. Microcapsules with $80: 20,75: 25$, and $65: 35$ core-shell ratios were found to be stable up to $160^{\circ} \mathrm{C}$. At core-shell ratios $50 ; 50$ and below some fine particles of irregular shape are observed along with stable microcapsules. These fine particles do not melt and also remain stable up to $160^{\circ} \mathrm{C}$. These may be free MF resin powder. It is expected, as the amount of shell material is more than that utilized for forming microcapsules.

Figure 7 shows the optical micrograph of PCM microcapsules. Dark-coloured spherical microcapsules can be seen in the micrograph (a) captured at ambient temperature. When heated the microcapsules turns to transparent white at $60^{\circ} \mathrm{C}(\mathrm{b})$. This is due to the melting 

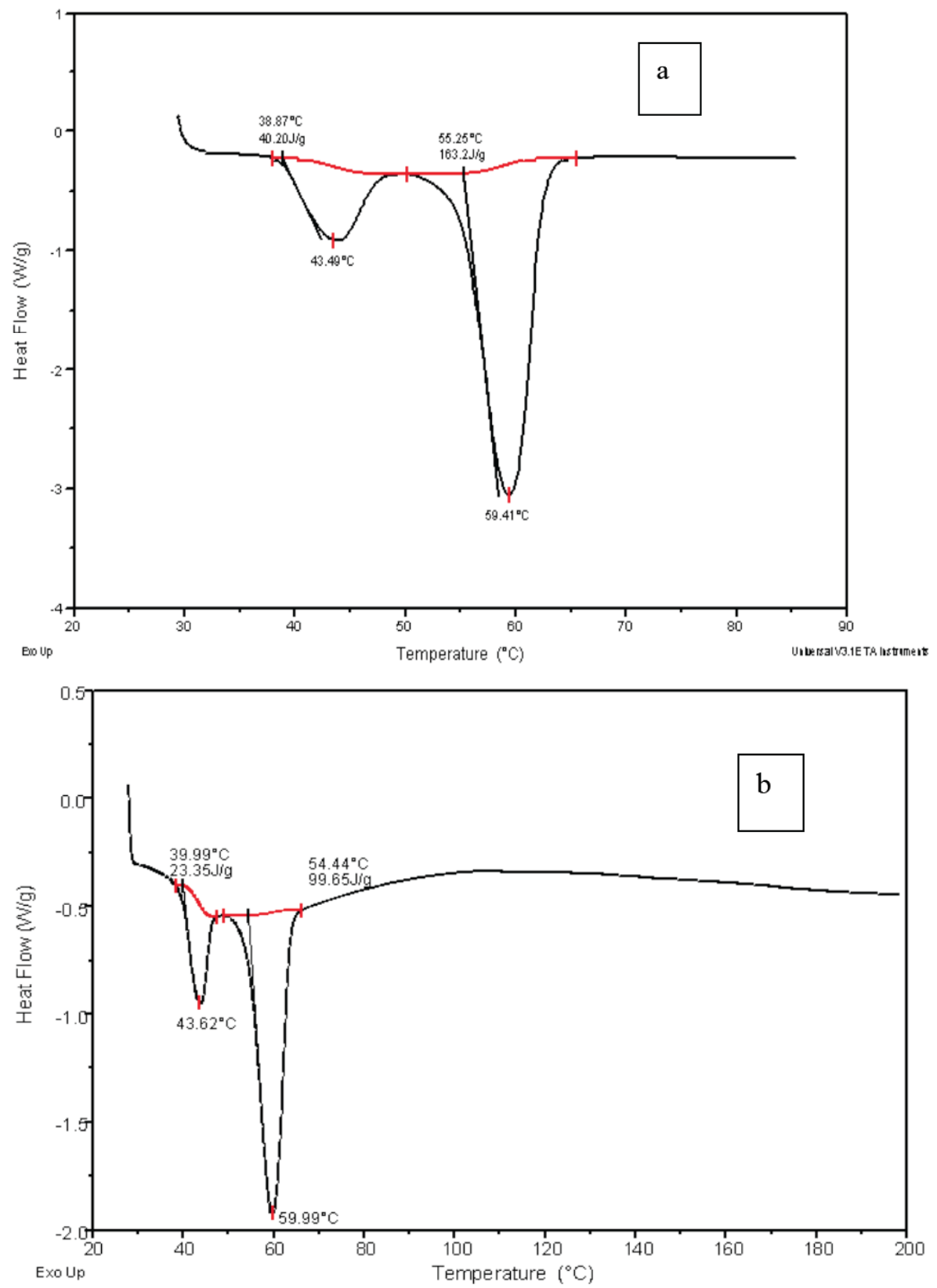

Figure 6: DSC thermo grams of PCM capsules, (a) Free wax, (b) Encapsulated wax.

Table 1: Core-Shell Characteristics of Microcapsules

\begin{tabular}{|c|c|c|c|}
\hline Core & Shell & Core to shell ratio & Remarks \\
\hline \hline 75 & 10.3 & $88: 12$ & Free wax found \\
\hline 63 & 10.3 & $85: 15$ & $\begin{array}{c}\text { Capsules were fragile and broken when heated to } \\
\text { melting temperature, due to very thin shell }\end{array}$ \\
\hline 43 & 10.3 & $80: 20$ & capsule were stable up to $180^{\circ}$ \\
\hline 32 & 10.3 & $75: 25$ & capsule were stable up to $180^{\circ}$ \\
\hline 19 & 10.3 & $65: 35$ & capsule were stable up to $180^{\circ}$ \\
\hline 10.3 & 10.3 & $50: 50$ & Free polymer powder was found \\
\hline 5 & 10.3 & $32: 58$ & Free polymer powder was found \\
\hline
\end{tabular}




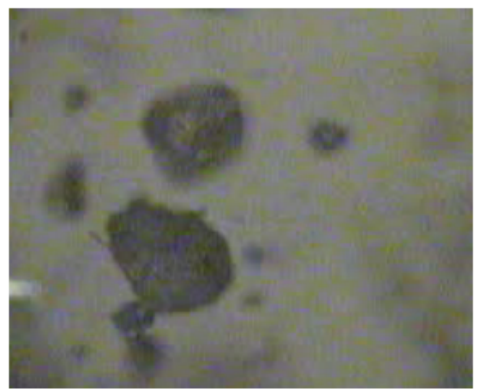

(a)

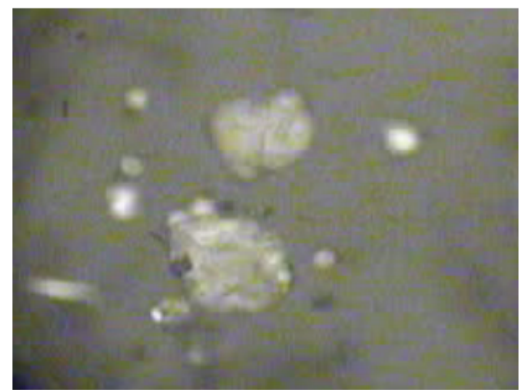

(b)

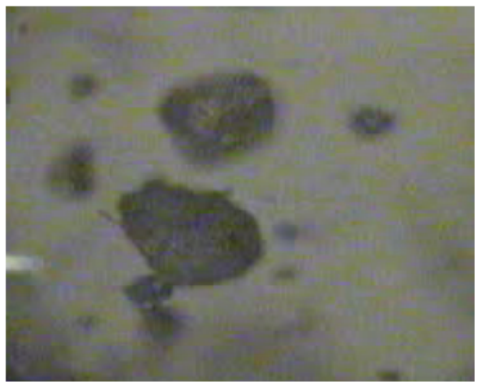

(c)

Figure 7: Hot stage optical microscope images: At room temperature (a); At $60^{\circ}$ (b); and after cooling to room temperature (c).

of wax present in microcapsules. During melting the crystallites turn amorphous and isotropic. Therefore, the region appears bright. This originates from the use of bright/dark field analysis strategies. Microcapsule again turns dark when cooled to ambient temperature(c). Microcapsules were subjected to several cycles of heating/ cooling. It is observed that capsules except 90:10 and 85:15 core-shell ratios are stable at working temperature. No degradation or change in behavior has been observed after repeated heating/cooling cycles.

\section{Performance Evaluation of Microcapsules}

The cooling performance of capsules was studied with respect to control temperature and it was measured at regular intervals of 30 seconds, and the temperature was plotted against time. A similar study on the heat storage-dissipation performance and thermal stability of the sugarcane wax-based composite PCM layer was reported by Tangsiriratana et al. [25]. From Figure 8a it can be seen that the initial drop in temperature of the medium is much faster in presence of microcapsules with PCM as compared to that without PCM. Which can be attributed to the absorption of heat by PCM in the capsules during its transformation of phase change solid to molten liquid?

$$
\text { In Figure } \mathbf{8} \mathbf{b}, \frac{\left(t_{i}-t_{f}\right)}{t_{i}} \text { (where, } t_{\mathrm{i}}=\text { initial }
$$

temperature, $t_{f}=$ final temperature) is plotted against time for experimental sample and control. The slope of the plot for PCM containing microcapsules is almost 3 times higher than that of the control (without PCM). This is due to fact that encapsulated wax absorbs a large amount of heat during melting and results in a quick fall in temperature reduction is due to radiation loss only. This behavior establishes the effectiveness of encapsulated PCM for the thermal management of confined space with a heat source. The slope of the plot for PCM containing microcapsule is almost 3 times higher than that of the control (without PCM). This is due to the fact that encapsulated wax absorbs a large amount of heat during its melting and results in a quick fall in temperature. A container without PCM shows slow cooling as the temperature reduction is due to radiation loss only. This behavior establishes the effectiveness of encapsulated PCM for the thermal management of confined spaces with a heat source.
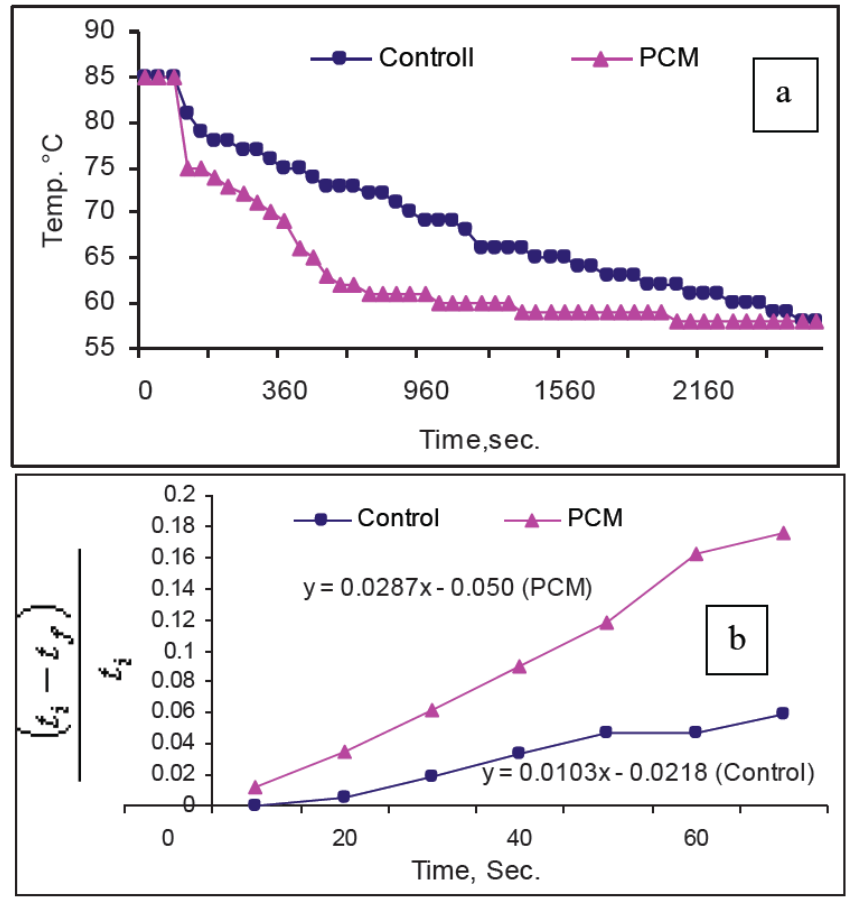

Figure 8: Performance of PCM capsules: Plot of temperature of the system with time during heat release $(a)$; Plot of $\left(t_{i}-t_{f}\right) / t_{t}$ vs. time for during its transformation of phase change solid to molten liquid (b).

\section{CONCLUSIONS}

Paraffin wax (PCM) was successfully encapsulated in melamine formaldehyde shell, with a core to shell ratio of 80:20. The average particle size of microcapsules was 100 microns and the Shell thickness was around $0.45 \mu \mathrm{m}$. Microcapsules were showing no leakage of wax during melting. Hot stage optical microscope has exhibited a change of 
appearance during melting and subsequent crystallization. SEM micrographs exhibited rough morphology of microcapsules. The broken microcapsules show the presence of a gap in between shell and core that indicates the presence of sufficient space during expansion because of melting. The decrease of melting enthalpy of PCM incorporated microcapsules is well understood due to the presence of non-PCM shells as diluent. Encapsulated PCM showed fast cooling of a medium at a temperature higher than the melting point of the wax. Which can be useful to maintain the temperature in a confined space with a heat source. However, this provides an effective solution in the case of pulsating type heat source? For continuous heat source this can be augmented with active cooling systems for better efficiency.

\section{REFERENCE}

[1] Abhat A. Sol Energy 1983; 30: 313 https://doi.org/10.1016/0038-092X(83)90186-X

[2] Farid M, Kong W. Proceedings British Institute of Mech. Eng., 2001; Vol. 214, part A, 601-609. https://doi.org/10.1243/0957650011538839

[3] Athentis AK, Liu C, Hawes D, Banu D, Feldman D. Building and Environment 1997; 32: 405-410. https://doi.org/10.1016/S0360-1323(97)00009-7

[4] Sbrandstetter A, Kaneff S. Proceedings 1st world renewable energy congress 1990; 1460-1464.

[5] Feldman D, Shapiro MM, et al. Solar Energy Materials 1986; 13: $1-10$. https://doi.org/10.1016/0165-1633(86)90023-7

[6] Ure Z. Positive temperature eutectic energy storage systems. CIBSE/Ashrae Conference 2003, England, UK 2003.

[7] Kelly R. (Undated), Latent heat storage in building materials. CIBSE. (Chartered Institute of Building Services Engineers).

[8] Kaasinen H. Solar Energy Materials and Solar Cells 1992; 27: 173-179. https://doi.org/10.1016/0927-0248(92)90118-9

[9] Technology briefing, Phase change materials overview, Centre for Sustainable Engineering, 2005, 25 Priest gate, Peterborough, PE1 1WG, www.cseng.org.uk

[10] Kaul RK. U.S. Patent 6,939,610 2005 https://doi.org/10.1016/B978-343723340-1.50046-0

[11] Yoshizawa $\mathrm{H}$. Trends in microencapsulation research, KONA 2004; No. 22: 23-31.

https://doi.org/10.14356/kona.2004009
[12] Green BK, Shleicher L. US patent, 2800457, CA 1957, 51: $15842 d$.

[13] Xiao-Zheng T, Zhi-Cheng, Z, Guang-Long S, Li-Xian, Zhang T. Chinese Journal of Chemistry 2004; 22(5): 411-414.

[14] Brown EN, Kessler MR, Sottos NR, White SR. In situ poly(urea-formaldehyde) micro encapsulation of Dicyclopentadiene j. micro encapsulation 2003; 20(6): 719730.

https://doi.org/10.1080/0265204031000154160

[15] Mulligan JC, Colvin DP, Bryant YG. J Space Rocket Reports 1996; 332: 278 https://doi.org/10.2514/3.26753

[16] Lee YH, Kim CA, Jang WH, Choi HJ, John MS. Polymer 2001; 42: 8277-8283. https://doi.org/10.1016/S0032-3861(01)00342-1

[17] Zhang XX, Tao XM, Yick KL, Fan YF. Journal of Applied Polymer Science 2005; 97: 390-396. https://doi.org/10.1002/app.21760

[18] http://www.engineeringtoolbox.com/thermal-conductivityd_429.html, Accessed 20 June, 2021.

[19] Mann A, Bürgel CM, Groche P. A Modeling Strategy for Predicting the Properties of Paraffin Wax Actuators.

[20] Yu J, Li H, Kong L, Zhu H, Qingshan, Wang H. Effects of Nanofilled Particle Forms and Dispersion Modes on Properties of Carbon-Based Energy Storage Composites Volume 2020; Article ID 6865497. https://doi.org/10.1155/2020/6865497

[21] Zhang $\mathrm{H}$, Li $\mathrm{W}$, Huang $\mathrm{R}$, Wang $\mathrm{N}$, Wang J, Zhang $\mathrm{X}$. Microstructure regulation of microencapsulated bio-based: $\mathrm{N}$ -dodecanol as phase change materials via in situ polymerization. New J Chem 2017; 41(23). https://doi.org/10.1039/C7NJ02864D

[22] Merline DJ, Vukusic S, Abdala AA. Melamine formaldehyde: curing studies and reaction mechanism. Polyme J 2013; 45 413-419.

https://doi.org/10.1038/pj.2012.162

[23] Zalba B, Marin JM, Cabeza LF, Mehling H. Review on thermal energy storage with phase change: materials, heat transfer analysis and applications. Applied Thermal Engineering 2002; 23(3): 251-283. https://doi.org/10.1016/S1359-4311(02)00192-8

[24] Naikwadi AT, Samui AB, Mahanwar PA. Fabrication and experimental investigation of microencapsulated eutectic phase change material-integrated polyurethane sandwich tin panel composite for thermal energy storage in buildings. Int $\mathrm{J}$ Energy Res 2021; 1-12. https://doi.org/10.1002/er.7138

[25] Tangsiriratana E, Skolpap W, Patterson RJ, Sripraphac K. Thermal properties and behavior of microencapsulated sugarcane wax phase change material. Heliyon 2019; 5(8): e02184

https://doi.org/10.1016/j.heliyon.2019.e02184

(C) 2021 Pawar et al.; Licensee Lifescience Global.

This is an open access article licensed under the terms of the Creative Commons Attribution License (http://creativecommons.org/licenses/by/4.0/) which permits unrestricted use, distribution and reproduction in any medium, provided the work is properly cited. 